\title{
In memoriam: Stefan Hohmann
}

\author{
Anders Blomberg ${ }^{1} \cdot$ Per Sunnerhagen ${ }^{1} \cdot$ Markus J. Tamás $^{1}$
}

Accepted: 23 August 2021 / Published online: 19 September 2021

(c) The Author(s), under exclusive licence to Springer-Verlag GmbH Germany, part of Springer Nature 2021

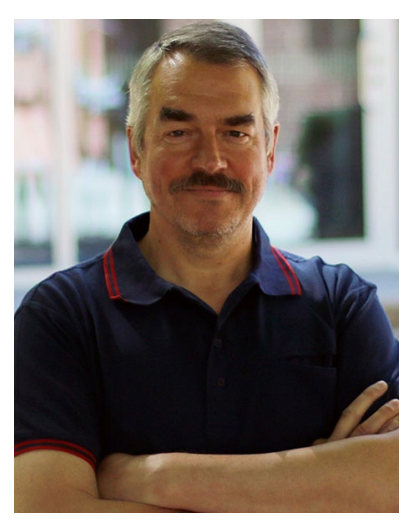

Stefan Hohmann

Stefan Hohmann has sadly left us, after battling for several years against illness. Stefan was a central figure in the international scientific community of yeast genetics, functional genomics, and systems biology for many years. He was previously the editor-in-chief of Current Genetics and of its sister publication Molecular Genetics and Genomics. ${ }^{1}$

Stefan earned his PhD at the University of Darmstadt, and subsequently became a group leader at the Katholieke Universiteit Leuven. As he was awarded a prestigious grant as Research Professor from the Swedish Research Council, he then moved to Gothenburg-first to the University of Gothenburg where he spent the major part of his career, and then to Chalmers University of Technology.

Stefan's research focused on signal transduction events, stress responses and transport proteins, primarily related to osmotic stress in yeast. Soon after completion of the first

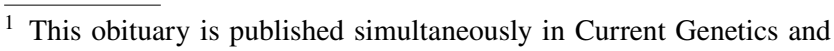
Molecular Genetics and Genomics.
}

Per Sunnerhagen

per.sunnerhagen@cmb.gu.se

1 University of Gothenburg, Gothenburg, Sweden eukaryotic genome sequence, that of Saccharomyces cerevisiae, followed by a draft of the human genome, there was a strong international interest to develop this resource into a quantitative understanding of biology. The concept of systems biology was born. Stefan realised the potential of yeast as a central part of this endeavour and was a key person to establish the Yeast Systems Biology Network. He successfully applied his main scientific interest: intracellular signal transduction, in particular the HOG pathway and its central role in osmoregulation, to this philosophy. This led to longstanding collaborations with mathematicians and modellers, as well as quantification of signalling events on the singlecell level. Topics spun around these central themes were the basis for the research group that he led for a long time. A large number of $\mathrm{PhD}$ students and postdocs, many of them international recruits, joined his group over the years.

Fostering a collaborative spirit and promoting interactions between scientists in yeast-related fields, Stefan organised seminars and yearly retreats for the local yeast community in Gothenburg, which by then had grown to be one of the most numerous in northern Europe. To these events, scientists were also invited from related fields such as bioinformatics, biochemistry, medicine, mathematics, and physics. This enhanced the cross-disciplinary atmosphere that Stefan always embraced. Encounters with Stefan's group laid the ground for the careers of many young scientists. For this, his vast international network was an important asset. Being a true European, Stefan coordinated several EU-funded research projects and networks, with participants from many European countries. He organised EMBO and FEBS courses and workshops for PhD students and postdocs. Stefan also arranged large international conferences in Gothenburg. In 2003, he was the main organiser of the 21st International Conference on Yeast Genetics and Molecular Biology, which still holds the record number of participants in this series, with over 1100 conference attendees. In 2010 he organised the 35th FEBS Conference together with the Norwegian Biochemical Society. And in 2019, despite already affected by illness, again Stefan was main organiser of an International 
Conference on Yeast Genetics and Molecular Biology in Gothenburg, this time the 29th.

Outside of the sphere of science, Stefan entertained several interests and passions. He was a wine connoisseur. Out of this passion, he did develop a scientific angle, obviously through the connection to yeast. For many years, he had close interactions with wine makers and scientists, in particular in Stellenbosch and Bloemfontein, South Africa. He took this interest to another level by initiating and co-directing a university-level education in Gothenburg in wine making, a pioneering event in Sweden. For this, he drew on his expertise in viticulture, wine production, terroir, and yeast strains. Another passion was football. On the larger scale, he was an ardent supporter of FC Bayern München; closer to home he supported the very local football club and also acted as coach (in particular for goal keepers) and referee for the young boys' team in Lerum where he lived with his family, and IFK Göteborg.
We remember Stefan as a generous and enthusiastic person, always supportive of young scientists and colleagues. He had a view for advancing science, its wider role in society, and for creating successful scientific communities. We are honoured to have collaborated with him scientifically, and to have come to know him as a friend. He will remain in our memory.

Friends and colleagues at the University of Gothenburg.

Anders Blomberg Per Sunnerhagen

Markus J. Tamás

Publisher's Note Springer Nature remains neutral with regard to jurisdictional claims in published maps and institutional affiliations. 